\title{
Professional Training of Specialists in Audio-Visual Art: Problems and Prospects
}

\author{
Zoya I. Alforova \\ Kharkiv State Academy of Design and Arts
}

\author{
Serhii I. Horevalov \\ Taras Shevchenko National University of Kyiv
}

Serhii M. Marchenko

Kyiv National I. K. Karpenko-Kary Theatre, Cinema and Television University

Svitlana V. Kotlyar

Kyiv National University of Culture and Arts

Kostiantyn V. Hrubych

Kyiv National University of Culture and Arts

The development of screen arts was a consequence of the synthesis of science and art, becoming part of the global system of technogenic arts. Various forms of on-screen creativity, such as cinema, television, video, digital art, interact more closely, both with each other and with conventional forms of cultural activity. The specificity of art, built on sound and visual images, lies in the artistic delivery of a world picture and the creation of screen works using optical, analogue, or digital systems. To study existing programmes and develop a training model for such specialists, the following study was carried out. The theoretical and methodological framework of the study included the general scientific principles of pedagogical research, the practical part included analysis and an experimental method of teaching and observation. The positive dynamics in the development of the subject competence of future specialists in the field of audio-visual arts testified to the effectiveness of the introduction of contextual technologies.

Keywords: television, cinema, training of specialists, university training

\section{INTRODUCTION}

Dynamic subculture movement of global media occurs against the background of the existence of different and situational needs of representatives of many subcultures; their elites, changes in the format of national and transnational media industries (Saglik and Ozturk, 2001; Ovcharenko, 2013; Glebova, 2016; Ismail and Ismail, 2017; Yevtushenko and Kovalova, 2019). Modern television broadcasting is also undergoing certain changes under the influence of these processes: there is a diversification of information 
sources; digital technologies are being updated, which develop the production cycle on television and its final product (Flores and Tran, 2021). The media innovation process considerably affects cognition both in the academic environment and in the field of professional media education. The volumes of visual information have been increased, the development of modern "knowledge" on its basis serves as the condition for the existence of many modern higher educational institutions (Kobrossy, 2019). The risk of "crowding out" the human subject by artificial intelligence during the development of "academic knowledge" is discussed by both teachers and students of higher educational institutions. The heuristic value of knowledge, its truthfulness, is questioned, since in this context a higher educational institution is considered as a certain "factory of simulacra of truth" where a student acquires only "empty signs" without a clearly fixed denotation, and science, along with its "stronghold", a higher educational institution, risk being trapped. Processes in media education are also changing. The professional thinking of a specialist in the modern media sphere becomes similar to the well-known "second-order author", moreover, the collective one, whose functions are automated by technology and they become responsible only for two industrial parameters: time and money. The time that he or she (the author) spent on distributing TV content to each individual customer, and the money that he or she (the author) received for this. Therewith, the thinking of the individual customer of television content is becoming more complex and discrete, on the one hand, but also active and flexible, on the other hand. The basis for this is communication with television - the newest sign of the use of digital technologies, not only informs and allows to enjoy various kinds of spectacles, but also allows to directly (or indirectly) contact with the television itself. The increased dialogicity of modern digital television is its main communicative and cognitive feature (Fleming, 2014; Budilov et al., 2017; Berger and Foote, 2017; Navarro Romero and Gómez Alonso, 2017; Carvalho and Vieira, 2019; Demianenko, 2017; Jakobsson and Stiernstedt, 2018). In this complex socio-cultural and information-cultural contexts, certain trends in the modernisation of modern professional higher education arise: the transition to digital technologies, the diversification of educational institutions, the transformation of a teacher-lecturer into a teacher-tutor, an increase in the volume of "optional disciplines" that allow the student to develop an individual scheme for acquiring knowledge, acquiring skills and abilities (Gavran et al., 2021).

In Ukraine, the entire sphere of education is being actively reformed in connection with the upcoming accession to the European space. The reform has affected all levels of the educational system: from the Ministry of Education as the state body governing the system to the system of school and higher education. This fully affected the legal regulation of the educational industry and its regulatory support, that is, the approval of state standards. Thus, in the field of audio-visual art and production, the process of standardisation of personnel training has affected the first (bachelor's) and second (master's) levels of training for the industry (Mayo, 2020). The standards of these levels have undergone serious examination, were approved in 2019 and are currently valid throughout the country. The state standards for the preparation of the third level - Doctor of Philosophy (in our case - Doctor of Arts) are under development and the standard of the junior bachelor for art colleges is being finalised. Accordingly, the process of attestation of personnel preparing future specialists in this area and the process of accreditation (national and international) of professional educational programmes of universities have been radically modernised.

Therewith, according to the Law of Ukraine "On Education" (2017), the term "art education" was introduced, taking into account the specifics of training personnel for the field of art, and the Ministry of Culture and Information Policy of Ukraine monitors that the content of the educational institutions of higher education institutions in the field of culture and art meets the needs of industries and the market for the consumption of cultural services. Therewith, according to the Law, the provision on the autonomy of universities, which corresponds to the ideology of European education, is fully implemented.

Reforming higher education in the field of audio-visual art and production required a certain unification of propaedeutic training (at the junior bachelor's level), which allowed universities to provide a certain academic mobility of students and the subsequent nostrification of their diplomas, at the same time, the autonomy of universities allowed to provide an individual training trajectory for each student by strengthening the variable component of educational and professional programmes. It is precisely at solving the problem of such unification that the standardisation of the junior bachelor is aimed. In preparation for 
such a standardisation of the junior bachelor's level, another problem has emerged: a colossal shortage of art and culture colleges that train assistant-level personnel and personnel of technical professions for the audio-visual arts and production.

The opened problem seriously threatens the industry, since it is the personnel of this level that provide the basic professional layer of the corresponding labour market. Therewith, it is precisely the development of an extensive infrastructure of colleges of the corresponding profile that allows to solve another problem

- to prepare such a specialist to continue professional growth already in universities.

The purpose of the future unification of the sphere of audio-visual art and production is to standardise the technological complex of the production of screen products (digital standard) in accordance with labour market standards (with the corresponding changes in the state register of professions) (Prensky, 2001; Aguaded, 2012; Aguaded-Gómez and Pérez- Rodríguez, 2012; Chiu, 2019; Ross, 2017; Sidaty et al., 2017; Hermosa-Ramírez, 2020; Lindell et al., 2020). It is necessary to change the type of educational strategy: from being in a "closed" education system and declaring "openness" to real openness to European trends. In addition, to gradually change the position of educational management: from crisis to creative. Summing up, it is paradoxical that these typical signs of a crisis in the Ukrainian system of screen education are realised simultaneously. But the presence of such a paradoxical crisis in the Ukrainian system of on-screen education develops a tendency towards "selection", decreases in the rating system of the screen representation of the Ukrainian mentality. Correlation of the requirements for screen education with the new labour market conditions for specialists of the corresponding profile is a condition for further integration into European professional spaces

\section{MATERIALS AND METHODS}

The theoretical and methodological framework of the study includes the general scientific principles of pedagogical research, the fundamental provisions of pedagogical theory, the conceptual foundations of the theory of teaching creative disciplines, scientific articles of Ukrainian and foreign specialists on the becoming and development of specialists in the field of audio-visual arts in different countries of the world. In particular, with the help of the method of theoretical generalisation, the theoretical foundations of the development of the necessary competences of future workers in the audio-visual sphere of work, as an important component of the development of professional skills and achievements, were developed.

Theoretical level: analysis of scientific literature on the research problem; analysis of statutory documents regulating the educational process in institutions of additional, secondary, and higher professional education (State educational standards, curricula, etc.); generalisation, comparison, systematisation, classification, synthesis of theoretical positions, opinions, assessments; pedagogical design, modelling of systems and learning processes.

The method of systems analysis allowed to substantiate the conceptual foundations of systemic shifts in pedagogy; in general, they are consistent with the development of a new type of programme shocks, which are aimed at preparing more competent and independent workers in the field of audio-visual arts who will be capable of navigating new tools and use digital technologies in their work. The definition of the main problems and obstacles of the study, as well as the available ways to solve them, was developed based on a systematic approach to the development of scientific articles of both Ukrainian and foreign scientists, research of aspects of the development of pedagogy, as well as the original author's developments.

The practical part of the study includes the results of the experiment. The objects of the research were students of 20-22 years old at the $3^{\text {rd }}$ and $4^{\text {th }}$ years of universities that provide training for specialists in the field of audio-visual arts. In total, 545 students were involved in the experiment. The authors have implemented a complex of contextual learning technologies in the professional training of students, which, hypothetically, was supposed to generate an increase in the qualitative and quantitative indicators of the subject competence of future specialists. 


\section{RESULTS AND DISCUSSION}

Diversification of information sources, updating digital technologies that develop the production cycle on television and its final product, require updating the material and technical resources of the university. The development concept provides for the modernisation of the faculty television studio complex for podcasts. Currently, the active work of the specialised Internet site of the faculty can be combined with Internet TV and provide opportunities for podcasts. The programme of international technical assistance for the project under consideration could be an important source of improving the cultural and educational situation in the region, attracting a wide range of creative youth to the creation of new television content with a humanitarian-oriented aspect; this programme is one of the priorities of the national information policy. The project has a certain self-sufficiency and allows to present the region and the country in the international information space. Financing measures in this are planned in the Concept for the development of the university. The implementation of the material and technical part of the specified project for the modernisation of the faculty television studio complex for Internet broadcasting is based on the tendency to increase the interactivity of modern media industries, and although the enhanced interactivity of television does not eliminate certain communication and cognitive risks, such television can only serve as an instrument of limited dialogicity; the transculturality of the cultural and textual discourse of television content, supplemented by digital server technologies, produces only a certain "grey area" (or zone of transgression) between the universality of discourse and its particularity, where this dialogue is potentially possible; at this stage of the development of the faculty, such implementation is expedient. Despite the "problem areas" of such technology, digital television is an objective stage in the development of modern societies and a response to modern socio-cultural needs of a person. Thus, the substantive and organisational foundations of the Concept for the Development of the Sphere of Audio-visual Art and Production make provision for further actions regarding the process of incorporating domestic segments of media education into the structure of the European system in accordance with its standards.

The approved standards solved the issue of structuring the professional competence of a specialist, since the universal competences of the field of audio-visual art and production were identified. But a new problem has emerged, which is related to the modernisation of the National Qualifications Framework and the Directory of Occupations, since the latest version of the Directory, which was released in 2015, is outdated. As of 2020, up to 70 percent of professions in the field of audio-visual art and production have been updated in terms of content, and up to 30 percent - also in terms of name (Law of Ukraine "On State..., 2020).

The analysis of scientific literature allows to single out the following components in the structure of the professional competence of a future specialist in the artistic specialty: 1. Perceptual, which allows to determine the specificity of the perception of the surrounding cultural space by future specialists in the arts. 2. Motivational and emotional component, within which the motivation of students and activities in the field of culture and art and the emotional and sensory aspect of the designated profession are determined. 3. A cognitive component that reflects the necessary body of knowledge and skills of a future specialist in an artistic specialty, developed based on art pedagogy. 4. Organisational and activity component, according to which a future specialist in an artistic specialty acquires competence in the process of quasi-professional or professional activity itself. 5. The reflective-evaluative component, due to which the creative reflection of the obtained level of professional competence occurs and the place and role of art pedagogy in the process of developing professional competence is assessed.

The pedagogical conditions of the experimental method included a system of the following measures:

- Creation of an innovative environment for the professional training of preschool education students for artistic and aesthetic activities in conditions close to the future professional and pedagogical activities;

- The introduction of organisational and methodological innovations for the development of separate components of the subject artistic competence of the future teacher of preschool education. This innovation covers various printed and video materials, as well as some educational computer programmes, namely electronic and multimedia manuals, reference and 
information systems, training programmes for consolidating knowledge and monitoring programmes aimed at checking the work performed;

- Innovative and pedagogical orientation of the content of methodological disciplines and art disciplines at the university with the inclusion of contextual pedagogical technologies in the teaching of disciplines "Fine arts with methodology", "Teaching arts and crafts with methodology" and "Art production with the basics of design".

The purpose of the first information and operational stage (third year of study) was to give future teachers of preschool education an idea of their future profession, the specifics of the artistic and aesthetic education of pre-schoolers, the features of the system of psychological, pedagogical, methodological education, as well as artistic knowledge, practical artistic and creative abilities and possession of artistic techniques.

The main condition for the successful implementation of the information-operational stage is the creation of an innovative environment for the professional training of preschool educators in the field of artistic and aesthetic education, aimed at the self-fulfilment of the future specialist using contextual educational technologies. At this stage, the following pedagogical technologies have been applied in the practice of teaching the fundamentals of the fine arts with the management methodology: a lecture on solving problems and a practical lesson (actually educational activity), during which the objective context of professional activity is developed; practical exercises with elements of discussion, role-playing and simulation games, as well as modelling future professional activity (quasi-professional activity), contributing to the development of both the substantive and social context of future professional activity; research work of students, preparation of projects, teaching practice, implementation of term papers (educational and professional activities).

At a practical lesson on the methods of teaching the fine arts, students were invited to take part in a discussion on the topic "The role of conventional and modern interactive methods and techniques of teaching fine arts", and it was also proposed to justify the expediency of the study, teaching methods, heuristics, and problem setting for the development of children's creative abilities. In addition, the students had to develop a task of research, heuristic and problematic nature to help children master such fundamental aspects of artistic literacy as colour, shape, composition, volume, and space. In preparation for the above classes, students had to independently work on various educational and methodological literature to give a comparative description of these methods and substantiate the most reasonable point of view; they were also asked to illustrate a specific methodology by solving specific methodological problems. Such conditions are favourable for the development of the subject context of future professional activities.

Defence of the chosen position with the help of imitation technologies is implemented in practical classes, where students have the opportunity to illustrate their opinion by presenting a fragment of a lesson on the development of a certain artistic skill. Such classes are practice-oriented - students not only reproduce the knowledge gained during lectures, but also express their position and model the actions of both the teacher and the children in potential life situations; they analyse specific methodological situations and evaluate them from the standpoint of teachers and methodologists. Notably, the way the simulated situation develops is not predetermined and depends mainly on the actions of the "teacher" and "children"; thus, it allows to develop both the subject and the social context of future professional activity.

The purpose of the second activity-technological stage (the fourth year of study) is to develop in future pre-schoolers the ability to implement the functions of artistic and aesthetic education in real preschool education, to master general pedagogical and specific artistic technologies, and to practice using nonstandard creative techniques.

To achieve this goal, an optimal combination of theoretical and practical components of training 012 "Preschool education" students for artistic and aesthetic education was developed, which allows them to acquire general and professional competences (pedagogical, psychological, methodological and artistic) in the fine arts classes with teaching methods and the fundamentals of art production and design. To create the conditions for achieving the goal of the activity-technological stage, the authors of this study created the necessary artistic context for learning, optimised the independent and research work of students, and also developed contextual learning technologies that involve intellectual team activities, i.e., developing 
common ideas, conducting cognitive discussion and modelling various processes (simulation exercises, analysis of professional situations, trainings). Simulation technologies include the division of roles, simulation of situations and business games, which are subdivided into operational role-playing, problemoriented, educational role-playing, and educational-pedagogical. For example, educational and pedagogical games helped choose the best ways of teaching students the methods and techniques of real pedagogical activity in preschool institutions; the games also required students to know specific topics, as well as basic pedagogy, psychology, and fine arts teaching methodology.

Project-oriented education is aimed at the dynamic, innovative development of education at the university and ensuring the consolidated involvement of all departments of the faculty of screen arts and other structural divisions of the university. The current system of personnel training in creative workshops was supplemented by a system of projects, where students not only practice their professional skills and abilities, but also immerse themselves in an environment close to the realities of the film and television industry. The proposed project approach is based on the following principles: joint performance of tasks in creative groups, in composition close to real film and television production; design implementation of practical work.

The priority areas for the development of project education at the university:

- the development of synchronised curricula in specialties and areas of training creative personnel for cinematography and television;

- creation of a unified methodological base for conducting project activities within the framework of the educational process;

- synchronisation of term papers, educational and industrial practices, graduate qualification papers;

- creation of a unified educational field for students of creative specialties;

- providing a high level of audio-visual works within the framework of student filmmaking;

- development of project activities.

The main components of project education at the university include:

- content (the subject of the project must correspond to the direction of the student's training);

- the ability to acquire key competences (creativity, communication, problem thinking, etc.);

- involvement in the educational process;

- presence of an open question or problem to be solved;

- the need for an unassisted search for information;

- independence in solving the problem;

- constant monitoring of the results of project activities;

- public defence of project results.

To isolate the cluster of project activities in all courses of study, a systematic change and synchronisation of curricula in all specialties and areas of training of the faculty of screen arts was carried out. Clusters of project activities were developed according to blocks of term and final qualification papers, educational and industrial practices. Such synchronisation allows Screen arts students collaborate on the development and production of audio-visual works, learning to work in a team, aim at achieving results and within a limited period (Marfil-Carmona and Chacón, 2017; Nori and Abdulmajeed, 2021).

The mechanism for implementing the project approach includes the following elements:

- development and implementation of the concept of project education (the Concept);

- elaboration and implementation of the development programme for the faculty of screen arts for 2016-2019 in order to implement the main provisions of the Concept;

- consideration of the main provisions of the Concept in statutory and methodological materials;

- development, approval of development programmes for the departments of the faculty of screen arts for 2017-2019;

- creation and organisation of the university as one of the key regulators of the student filmmaking process and the implementation of creative projects at the university; 
- development and approval of basic educational programmes in specialties and areas of training at the university and relevant curricula, taking into account the main provisions of the Concept. The implementation of project-based learning will provide the following results:

- creation of a professional television and cinematographic environment from the first year of study at the university;

- implementation of the conditions for interaction of representatives of all specialties and areas of training necessary for the television and film industry;

- effective preparation of future creators for the real conditions of television and film production through the participation of students in regular pitches, the development of projects for audiovisual works, in the preparation of staging projects, in filming and in post-production work as part of creative teams;

- creation of student audio-visual works that can compete in the film and television market (to gain recognition from the cinematic community).

Thus, the project approach allows to model processes that are close in their goals, objectives, and organisation to the realities of film and television production, which allows the successful integration of graduates into the professional environment. The establishment of a creative environment at the university and interdisciplinary integration allow for a harmoniously developed personality, which in turn is an integral quality of a successful and sought-after specialist in the field of audio-visual art and production.

\section{CONCLUSIONS}

The positive dynamics in the development of the subject competence of future specialists in the field of audio-visual arts testifies to the effectiveness of the introduction of contextual technologies. The process of training future media professionals in universities can improve if they consistently introduce such contextual technologies as modelling, imitation games, master classes, and creative workshops in their training.

This study allowed to answer to the questions whether the strategy of contextual educational technologies is effective in the development of the subject competence of future preschool educators in the artistic and aesthetic education of children; what types of contextual technologies are most effective in the professional training of a future teacher; whether the introduction of contextual technologies in the process of professional training of students would lead to an increase in the quality indicators of the subject competence of future specialists in the field of audiovisual arts.

Thus, the effectiveness of the strategy of contextual educational technologies in the development of the subject competence of future specialists in the field of audiovisual arts was proved. Contextual learning technologies allow creating conditions for the interpenetration of academic and future professional activities as one of the ways to achieve professional competence.

\section{REFERENCES}

Aguaded, J.I. (2012). United Nations aiming at Media Literacy Education. Comunicar, 38, 7-8.

Aguaded-Gómez, I., \& Pérez-Rodríguez, M. (2012). Strategies for media literacy: Audiovisual skills the citizenship in alusia. Journal of New Approaches in Educational Research, 1(1), 22-26.

Berger, G., \& Foote, R. (2017). Taking Stock of Contemporary Journalism Education: The End of the Classroom as We Know It. In R.S. Goodman \& E. Steyn (Eds.), Global Journalism Education in the 21st Century: Challenges Innovations. Austin: Knight Centre for Journalism in the Americas.

Budilov, V., Danilov, P., \& Rtischeva, T. (2017). A project-based approach to film education: Transformation of the training system for cinematography and television. Petersburg Economic Journal, 3, 16-23.

Carvalho, A., \& Vieira, C. (2019). Narrativity and audio-visual performance: Meaning in the narrative experience. Journal of Science and Technology of the Arts, 11(1 Special Issue), 2-31-2-40. 
Chiu, J.S. (2019). Better education and training in apologies to resolve medical mishaps disputes. Medicine and Law, 38(1), 59-72.

Demianenko, O.O. (2017). Evolution of scientific research in media education: Critical thinking of an individual as the primary component of modern media education. Narodna Osvita, 1(31), 68-73.

Fleming, J. (2014). Media Literacy, News Literacy, or News Appreciation? A Case Study of the News Literacy Program at Stony Brook University. Journalism \& Mass Communication Educator, 69(2), 146-165.

Flores, B., \& Tran, T. (2021). Use of neural networks in the formation of a high-quality smoothed audio signal. Scientific Herald of Uzhhorod University. Series "Physics", 49, 35-42.

Gavran, I.A., Hutsal, R.S., \& Tsaruk, S.M. (2021). Motivation as a core aspect of the development of professional skills and abilities in the period of distance learning of art students. Scientific Bulletin of Mukachevo State University. Series "Pedagogy and Psychology", 7(3), 94-101.

Glebova, I. (2016). The Development of the screen arts and their impact on audio-visual education in America. Interactive Science, (7), 6-9.

Hermosa-Ramírez, I. (2020). Delivery approaches in audio description for the scenic arts. Paralleles, $32(2), 17-31$.

Ismail, A., \& Ismail, R. (2017). Knowledge versus Experience: Indicator to Good Journalism Practices. Jurnal Komunikasii, Malaysian Journal of Communication, 33(4), 142-158.

Jakobsson, P., \& Stiernstedt, F. (2018). Naturalizing social class as a moral category on Swedish mainstream television. Nordicom Review, 39(1), 81-94.

Kobrossy, Y. (2019). The inclusion of visually impaired students in a Lebanese private school: A case study. International Journal of Learning and Change, 11(2), 190-206

Law of Ukraine "On State Support of Cinematography in Ukraine". (2020). Retrieved from https://ips.ligazakon.net/document/T171977?an=1

Lindell, J., Jakobsson, P., \& Stiernstedt, F. (2020). The field of television production: Genesis, structure position-takings. Poetics, 80, 101-110.

Marfil-Carmona, R., \& Chacón, P. (2017). Arts Education Media Literacy in the Primary Education Teaching Degree of the University of Granada. Procedia - Social Behavioral Sciences, 237, $1166-1172$.

Mayo, J.W. (2020). Vertical integration and the evolution of audiovisual services: Economic policy implications for Brazil. Revista De Direito, Estado e Telecomunicacoes, 12(1), 1-8.

Navarro Romero, R.M., \& Gómez Alonso, J.C. (2017). The validity of rhetorical categories in audiovisual culture. Bajo Palabra, (14), 83-94.

Nori, A.S., \& Abdulmajeed, A.O. (2021). Design and implementation of Threefish cipher algorithm in PNG file. Sustainable Engineering and Innovation, 3(2), 79-91.

Ovcharenko, N.A. (2013). Professional training of future teachers of musical art in Ukraine: Problems, prospects. Bulletin of Tomsk State Pedagogical University, 13(141), 21-25.

Prensky, M. (2001). Digital Natives, Digital Immigrants. On the Horizon. MCB University Press, 9(5). Retrieved from http://www.nnstoy.org/download/technology/Digital\%20Natives\%20\%20Digital\%20Immigrants.pdf

Ross, A.A. (2017). If Nobody Gives a Shit, is it Really News? Changing standards of news production in a learning newsroom. Digital Journalism, 5(1), 82-99

Saglik, M., \& Ozturk, S. (2001). Television as an educational technology: Using television at open education faculty, Anadolu university. Turkish Online Journal of Distance Education, 2(1), 74 82.

Sidaty, N., Larabi, M., \& Saadane, A. (2017). Toward an audio-visual attention model for multimodal video content. Neurocomputing, 259, 94-111.

The Verkhovna Rada of Ukraine. (2017). Law of Ukraine "On Education". Retrieved from https://zakon.rada.gov.ua/laws/show/2145-19\#Text

Yevtushenko, O., \& Kovalova, T. (2019). Media education for future media professionals: Designing implementing a training programme. Advanced Education, 12, 94-104. 